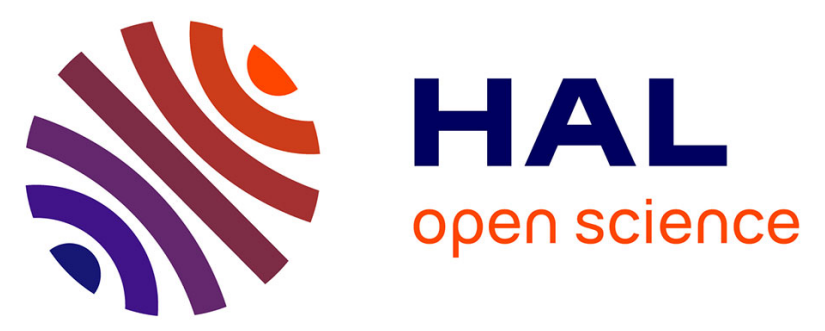

\title{
Long-term Safety and Efficacy of Local Microinjection Combining Autologous Microfat and Adipose-Derived Stromal Vascular Fraction for the Treatment of Refractory Perianal Fistula in Crohn's Disease
}

Mélanie Serrero, Fanny Grimaud, Cecile Philandrianos, Carine Visée, Florence Sabatier, Jean-Charles Grimaud

\section{To cite this version:}

Mélanie Serrero, Fanny Grimaud, Cecile Philandrianos, Carine Visée, Florence Sabatier, et al.. Longterm Safety and Efficacy of Local Microinjection Combining Autologous Microfat and Adipose-Derived Stromal Vascular Fraction for the Treatment of Refractory Perianal Fistula in Crohn's Disease. Gastroenterology, 2019, 156 (8), pp.2335-2337.e2. 10.1053/j.gastro.2019.01.032 . hal-02555624

\section{HAL Id: hal-02555624 \\ https://hal-amu.archives-ouvertes.fr/hal-02555624}

Submitted on 26 Oct 2021

HAL is a multi-disciplinary open access archive for the deposit and dissemination of scientific research documents, whether they are published or not. The documents may come from teaching and research institutions in France or abroad, or from public or private research centers.
L'archive ouverte pluridisciplinaire HAL, est destinée au dépôt et à la diffusion de documents scientifiques de niveau recherche, publiés ou non, émanant des établissements d'enseignement et de recherche français ou étrangers, des laboratoires publics ou privés.

\section{(ㅇ)(1) $\$$}

Distributed under a Creative Commons Attribution - NonCommerciall 4.0 International 


\section{Title}

Long-term safety and efficacy of local microinjection combining autologous microfat and adipose-derived stromal vascular fraction for the treatment of refractory perianal fistula in

\section{Crohn's disease.}

\section{Authors' names}

Mélanie Serrero ${ }^{1,2}$, Fanny Grimaud ${ }^{3}$, Cécile Philandrianos ${ }^{4}$, Carine Visée ${ }^{5}$, Florence Sabatier ${ }^{3,6}$, JeanCharles Grimaud ${ }^{1,2}$

\section{Authors' institution}

${ }^{1}$ Gastroenterology Department, Assistance Publique Hôpitaux de Marseille, CHU of Marseille, Marseille, France

${ }^{2}$ Centre d'Investigation Clinique 1409, Assistance Publique Hôpitaux de Marseille, Aix Marseille University, France

${ }^{3}$ Cell Therapy Department, INSERM CBT-1409, Assistance Publique Hôpitaux de Marseille, Aix Marseille University, France

${ }^{4}$ Plastic Surgery Department, Assistance Publique Hôpitaux de Marseille (APHM), CHU of Marseille, France

${ }^{5}$ Digestive Surgery Department, Assistance Publique Hôpitaux de Marseille, $\mathrm{CHU}$ of Marseille, France

${ }^{6}$ Aix Marseille University, C2VN, INSERM UMR 1263, Faculté de Pharmacie de Marseille, France

\section{Corresponding author contact information}

Mélanie Serrero. Address: Service de Gastroentérologie, Hôpital Nord, Chemin des Bourrelly, 13015 Marseille, France. E-mail: melanie.serrero@ap-hm.fr

\section{Conflict of interest statement (for all authors)}

JC Grimaud has served as a consultant for AbbVie, Takeda and Janssen and as a speaker for AbbVie, Takeda, Janssen and MSD. The remaining authors disclose no conflicts.

\section{Author contributions to manuscript}

Study concept and design: JCG and FS. Collection and acquisition of data: JCG and MS. Analysis and interpretation of data: MS and FG. Management of patients' surgical treatment: 
$\mathrm{CV}$ and CP. Drafting of the manuscript: MS and FG. Critical revision of the manuscript for important intellectual content: FS and JCG. Study supervision: FS and JCG.

\section{Acknowledgements}

The authors are grateful to Julie Veran and the technical team of the APHM cell therapy unit who supervised the manufacture of cell products; to the staff of the hematology laboratory of APHM (Pr Françoise Dignat-George) for support in quality control assays; to Dr Jeremy Magalon who contributed to the interpretation of the data and critical revision of the manuscript; to Dr Caroline Prost and Jerôme Soussan who reviewed all patients' magnetic resonance imaging (MRI) examinations in a blinded fashion; to Elisabeth Jouve who provided methodological assistance in the study design and performed the statistical analysis; and to Dr Pierre-Charles Orsoni and Pr Dominique Casanova for sharing their expertise in the surgical aspects of treatment. We also acknowledge Professor Guy Magalon, who participated in the design of the trial and promotes innovative cell therapy within our university hospital.

\section{INTRODUCTION}

Perianal fistulas are frequent and morbid Crohn's disease (CD) complications that critically affect patient quality of life [1]. Despite the best available therapies, durable remission in complex perianal fistulas is achieved in only $37 \%$ of patients [2], and recurrence and postoperative anal incontinence remain frequent. Recently, cell therapies using expanded mesenchymal stem cells (MSCs) have shown promising effects [1]. The adipose-derived stromal vascular fraction (ADSVF) is an easily accessible source of cells with angiogenic, immunomodulatory and regenerative properties [3], but remains unevaluated in this context. We hypothesized that ADSVF combined with the trophic and volumizing effects of microfat grafting [4] could promote tissue healing. We reported the first clinical trial 
evaluating the injection of autologous ADSVF and microfat in the management of complex CD perianal fistulas.

\section{METHODS}

Patients were aged $>18$ years and diagnosed with complex perianal fistula associated with $\mathrm{CD}$ for at least 6 months with controlled luminal disease (Crohn's Disease Activity Index (CDAI) <220). Fistula(s) were refractory to conventional treatment defined as failure of at least one surgical treatment (including drainage and seton placement) associated with antiTNF therapy. Exclusion criteria included anal abscess, stenosis, severe proctitis and body mass index $(\mathrm{BMI})<18 \mathrm{~kg} / \mathrm{m}^{2}$. The patients were not excluded based on the number of fistula tracts. Patients were subjected to a first examination under anesthesia with drainage by seton placement, if indicated. The procedure was performed one week later and required two surgeries on the same day under anesthesia [5]. First, lipoaspiration was performed to acquire ADSVF using Celution 800/CRS (Cytori Therapeuthics Inc., California, USA). The second surgery involved microfat harvesting with a closed-circuit filtration system (Puregraft, CA, USA), preparation of fistula (seton removal, curettage of fistula tracts and suture of the internal openings) and the immediate injection of both microfat and ADSVF into the wall of the fistula and surrounding tissues. Patient characteristics and cell therapy procedures are detailed in the Supplementary Material.

Patients were monitored for safety at baseline and at 1, 2, 6, 12, 16 and 48 weeks after injection. Efficacy analysis included clinical evaluation of fistula, evaluation of disease activity by Perianal Crohn's Disease Activity Index (PDAI)/CDAl scores, and assessment of quality of life by the Small Inflammatory Bowel Disease Questionnaire (SIBDQ). Combined remission 
was defined as a complete cessation of suppuration of all the external openings confirmed via MRI assessment (absence of collections $>2 \mathrm{~cm}$ in three axes) at weeks 12 and 48 . Clinical response was defined as an evident decrease in the suppuration score.

\section{RESULTS}

Ten patients with a median age of 36 years (range, 19-63 years) were treated (Supplementary table 1). The median CD and fistula durations were 8 years (range, 2-38 years) and 4 years (range, $1-15$ years) respectively. Patients presented one $(n=4)$, two $(n=5)$ or three $(n=1)$ fistula tracts associated with one $(n=4)$, two $(n=3)$ or more than two $(n=3)$ external openings. A median of 22.8 million (range, 10.9-47.8 million) viable nucleated cells was injected including 38.4\% (range, 22.6-50.2\%) MSCs and 6.4\% (range, 3.9-15.7\%) endothelial cells. The median quantity of microfat injected was $10.8 \mathrm{~mL}$ (range, 5-17 mL).

Three serious adverse events (SAEs) occurred: two flares and one new fistula tract. They were moderate in intensity (grade 2) but categorized as SAEs because of the need for patient hospitalization. Non-serious adverse events were moderate pain at the lipoaspiration site (40\%) that resolved in less than one week under simple oral analgesia and a cutaneous reaction secondary to anesthetics. No case of posttreatment incontinence was described. Blood inflammatory parameters (C-reactive protein (CRP), fibrinogen, white blood count) were unchanged compared with baseline.

Seventy percent of patients had a clinical response at week 12 , and $80 \%$ at week $48 ; 20 \%$ and $60 \%$ of patients achieved combined remission at weeks 12 and 48 , respectively. In addition, 13 of 17 treated external openings showed complete re-epithelialization or an absence of drainage at week 48. Two patients showed complete occlusion of fistula tracts on 
MRI at week 48 [Figure 1A]. A significant improvement in perianal disease severity was observed with a decreased PDAl score (7.3 at baseline, 3.8 at week 12 and 3.4 at week 48, $p=0.002)$ and an increased quality of life score $(p=0.038)$ [Figure 1B].

\section{DISCUSSION}

We provide some of the first evidence that injection of the ADSVF and microfat is a feasible and safe treatment for CD perianal fistula [6]. The SAEs were typical and possibly related to the natural course of disease, although the impact of the treatment cannot be fully excluded, particularly for the occurrence of the new fistula tract.

The fistula improvement is noteworthy, as combined remission was observed in $60 \%$ of patients. This result is comparable to that reported for cultured MSCs [7]. The surgical procedure may play a key role in this therapeutic approach. However, Panes et al. [7] reported combined remission in $34 \%$ of patients in the "placebo group" (surgical procedure alone), whereas a significantly higher proportion of patients achieved combined remission after MSC injection (50\%). These data suggest an additional effect of cells compared with surgical treatment alone. As usually observed in phase I clinical trials, the procedure used heterogeneous doses of ADSVF cells recovered from a standardized lipoaspirat volume. Future studies should investigate the relationship between cell doses and healing effects.

Thus, the proposed procedure constitutes a promising alternative to more complex strategies requiring ex vivo expansion of stem cells and/or scaffolding materials [8]. Preclinical models have documented the superiority of ADSVF over purified stem cells for tissue repair owing to the heterogeneity of cells in the ADSVF [3]. The ADSVF also improves the efficiency of fat autografts used in soft tissue defects. Reciprocally, microfat acting as a 
plug and filler is likely to favor the local persistence of cell activities. Therefore, our results support the healing potential of two minimally manipulated autologous products, the ADSVF and microfat, that act in synergy to confer regenerative and volumizing effects.

While our findings should not be overinterpreted as a proof of benefit because of the low number of patients and the uncontrolled nature of the trial, they strongly encourage future evaluation of the efficacy of the ADSVF and microfat in placebo-controlled trials. Such trials will shed light on whether this strategy represents an easily accessible cell-based therapy with a favorable benefit-cost profile for refractory fistulizing CD patients.

\section{REFERENCES}

1. Kotze PG, et al. Gut 2018;67(6):1181-1194.

2. Molendijk I, et al. Inflamm Bowel Dis 2014;20:2002-2028.

3. Bora P, et al. Stem Cell Res Ther 2017;8:145.

4. Nguyen PS, et al. J Plast Reconstr Aesthet Surg 2012;65(12):1692-9.

5. Philandrianos C, et al. Stem Cell Res Ther 2018;9(1):4.

6. Garcia-Olmo D, et al. Int J Colorectal Dis. 2009 Jan;24(1):27-30.

7. Panes J, et al. Gastroenterology 2018;154(5):1334-1342.

8. Dietz AB, et al. Gastroenterology 2017;153(1):59-62.

\section{FIGURE LEGEND}

Figure 1. Efficacy outcomes. (A) MRI images at baseline, week 12 and week 48 . These perianal examinations based on MRI using T1 postcontrast (gadolinium) sequences show the disappearance of the fistula track (red arrow) at week 12, which was confirmed at week 48, indicating complete healing of the fistula. (B) Evolution of the PDAI and SIBDQ scores (mean and standard deviation) from before screening to week 48 after the procedure (PDAl: Perianal Crohn's Disease Activity Index, SIBDQ: Small Inflammatory Bowel Disease Questionnaire). ${ }^{*} p$-value $<0.05$ : Wilcoxon signed rank test adjusted for multiplicity. 


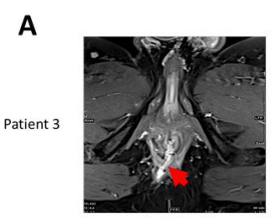

Before injection

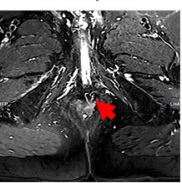

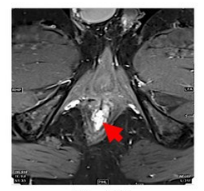

Week 12

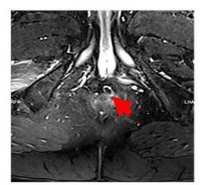

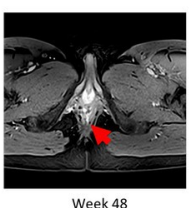

Week 48

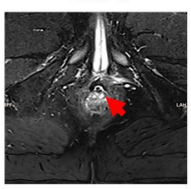

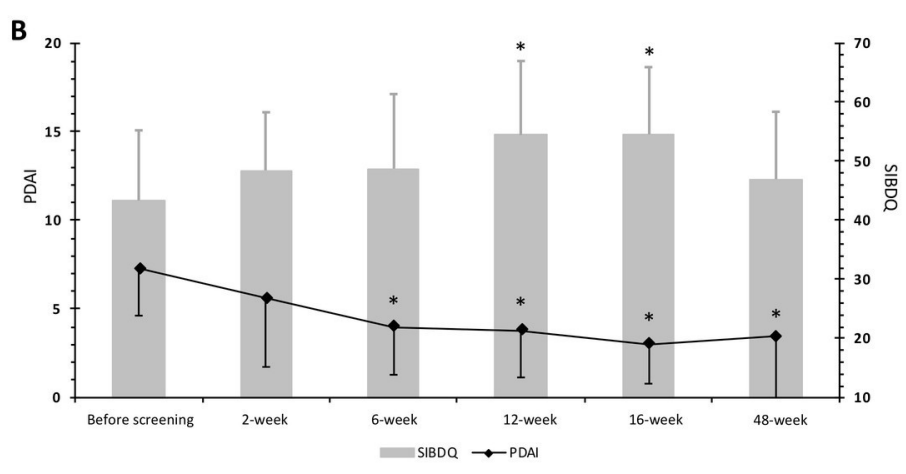

